\title{
A Study on the Impact of Rural Loans on Farmers' Income-Taking Shaanxi Province as an Example
}

\author{
Chen Chen \\ Shaanxi Normal University \\ Xi'an, Shaanxi China, 710062 \\ 475328529@qq.com
}

\begin{abstract}
Our objective in this paper is to study the impact of rural loans on farmers' income, taking Shaanxi Province as an example. We use a multiple linear regression model to analyze the per capita net income of rural residents and rural loans. It is concluded that the per capita net income of rural residents is positively correlated with rural loans, so the government should increase Financial support in rural areas.
\end{abstract}

Keyword-The problem of agriculture; Farmers and countryside rural loan income; Shaanxi Province

\section{INTRODUCTION}

China has a large population and it is also a big country in agriculture. At present, the income level of rural residents is low, and their spending power is weak. Compared with China's rapid economic development, there are still many problems in the development of rural areas. In the 1990s, the development of rural finance was mostly slow, and many bank branches gradually withdrew from rural areas. Beginning in 2005, a new round of rural financial reforms has begun. Governments at all levels have actively guided financial institutions to serve "three rural issues", and in particular increased their support for rural loans. This policy has achieved certain results. A group of new rural financial institutions have added vitality to the rural financial market. So whether the credit funds invested by financial institutions in rural areas have been effectively allocated, whether to promote the increase of farmers' income? According to American economist Lewis (W.A.Lewis, 2007), farmers in rural areas need far more to invest in agricultural production than they can raise for themselves, and government subsidies are feasible to meet farmers' need for capital. Hasody (M.Hasody, 2010) believes that it will be a long time if the development of their own production will drive their economic development. It is a must for the government and relevant financial institutions to provide them with loans.

Lin Yifu (2011) found through a large number of studies that China's domestic financial and financial support for rural areas is not very strong, the efficiency is still very low, but the overall aspect has a certain role in improving the income of rural households and promote rural welfare effect. Moreover, the famous scholar Guo Wei (2012) also studied that the majority of rural areas are the share of private lending has a large proportion, which is the informal financial institution model. However, even if loans from informal financial institutions have a significant impact on farmers' income, the role of correctly introducing formal financial institutions will be even greater. As a result, the development of rural finance has a great impact on the income of farmers, and it can better promote the increase of farmers' income, and further play its biggest role. Shaanxi Province, as a large agricultural province in the west, has many references for the development of rural loans in China. However, as a domestic study on Shaanxi Province is not too much, so this article has a great necessity for the study of Shaanxi Province.

\section{ANALYSIS OF RURAL LOANS AND FARMERS' INCOME IN SHAANXI PROVINCE}

Shaanxi Province is a large agricultural province. Among the many provinces in China, Shaanxi Province has typical guiding significance. According to statistical data of relevant data, by the end of 2015 , the total population of the province reached 37.93 million, of which the rural population was 17.48 million, and the rural population accounted for $46.08 \%$ of the total population. [Source: Statistical Yearbook of Shaanxi Province, 2015] Nowadays, the economic development of Shaanxi Province lags behind the central and eastern regions. By the end of 2015, Shaanxi's total GDP was 180.218 billion yuan, and rural GDP in Shaanxi Province was 159.763 billion yuan.

\section{A. Basic status development of rural loans and rural financial institutions in Shaanxi Province}

\section{1) Development of rural loans in Shaanxi Province}

Loans in rural areas, as the main channel for the acquisition of farmers' funds, can solve the problems of farmer's agricultural production and farmers' income. The development of rural loans in Shaanxi Province can be derived from the number of loans to financial institutions from rural areas at or below the county level. This article mainly collects and summarizes the total amount of rural loans for Shaanxi Rural Finance Yearbook 2001-2015, as shown in the figure below. 


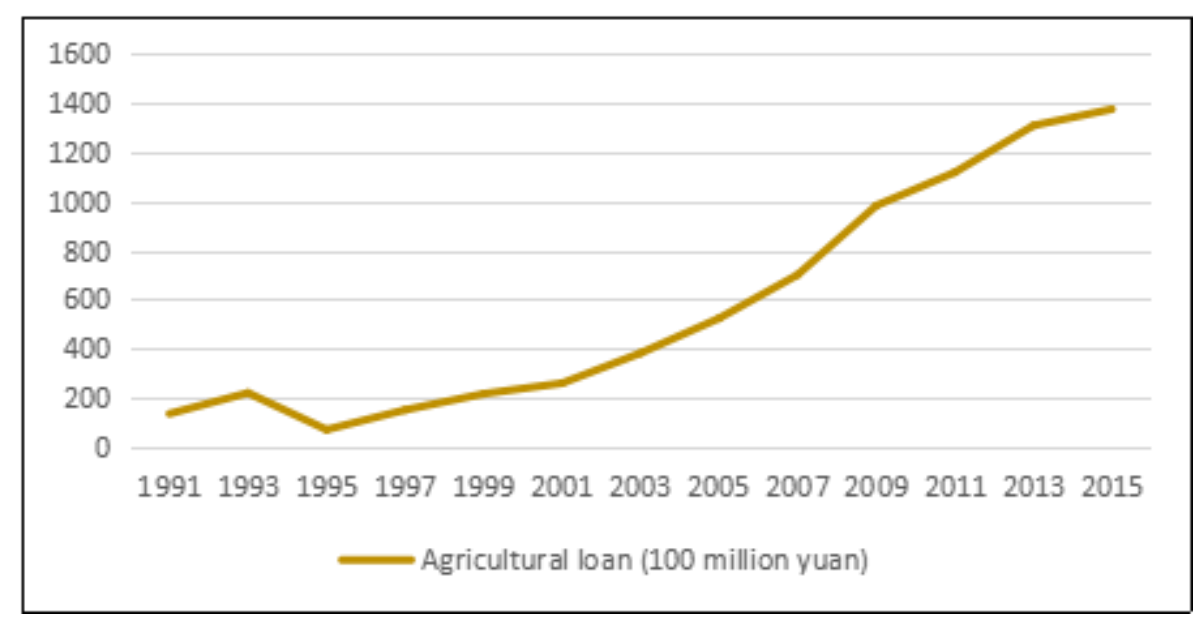

Fig. 1 Total Rural loans in Shaanxi Province 2001-2015

From the 2-1 chart, it can be seen that by the end of 2015 , the total loans of formal financial institutions in rural areas reached 199.283 billion yuan. The total amount of rural loans in Shaanxi Province showed an increasing trend in 2001-2005.The total amount of rural loans in 2006 was slightly lower than the total amount of rural loans in 2005. But 2006-2015 is still growing and growing fast.

Development of Rural Financial institutions in Shaanxi Province
Source: statistical Yearbook of Shaanxi Province 2001-2015

In 2015, statistics showed that there were 4,265 financial institutions in rural areas in Shaanxi Province. Since 2007 and 2014, the number of rural banks in Shaanxi Province has expanded rapidly, indicating the rapid growth of rural banks in Shaanxi Province.

\section{B. The basic situation of Rural residents' income in Shaanxi} Province

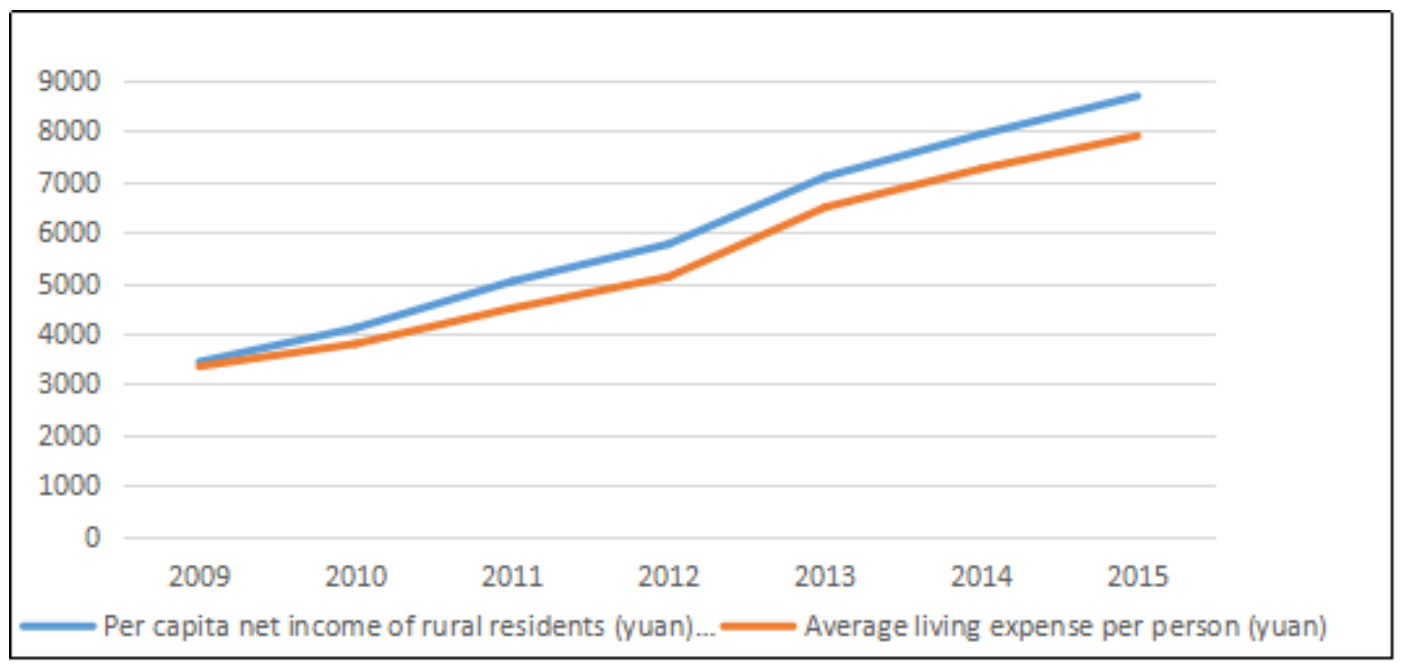

Fig. 2 Rural per capita net income and per capita living consumption expenditure of rural residents in Shaanxi Province 2009-2015

In 2011, farmers per capita net income of 5028 yuan, per capita living expenses of 4496 yuan. By 2015, the per capita net income of farmers will be 8689 yuan, and the per capita living expenses will be 7901 yuan.

\section{AN EMPIRICAL STUDY ON THE IMPACT OF RURAL LOANS ON FARMERS' INCOME IN SHAANXI PROVINCE}

\section{A. Measurement methods and data description}

This paper selects the per capita net income of rural residents as the index to measure farmers' income. Since the amount of rural loans in Shaanxi Province is an indicator of the total amount of loans at the macro level, the loan balance of local and foreign currency financial institutions at or below the county level is divided by the number of rural population to obtain the amount of loans per capita in Shaanxi Province. The data mainly come from Shaanxi Province financial statistics 
yearbook over the years. Other factors that affect the per capita net income of rural residents are agricultural investment and so on. Agricultural investment is also a concept of total amount, so divide the total amount of agricultural investment by the number of rural population, and get a per capita amount of agricultural investment.

This paper deals with the panel data of the five variables of rural residents' per capita net income (unit: yuan), total rural loan amount (100 million yuan), rural investment (100 million yuan), rural loan per capita (yuan) and rural investment per capita (yuan) from 2001 to 2015. The data are from the people's Bank of China, the Financial Yearbook of China and the Statistical Yearbook of Shaanxi Province.
Considering the availability of data and the literature review, the following linear regression models are established to analyze rural income and the amount of rural loans per capita. The models are as follows:

$$
y=\beta_{0}+\beta_{1} x_{1}+\beta_{2} x_{x}+\mu
$$

The dependent variable denotes the per capita income of rural residents, and is the constant coefficient of the model, and the coefficient is the coefficient of the per capita rural loan, and the coefficient is the coefficient of the per capita rural loan, in which the per capita agricultural investment is represented by the per capita investment, and the error is the error term. The above model is the model of this paper to study the impact of rural loans on farmers' income.

TABLE I RELEVANT INDICATORS OF THE 2001-2015 MODEL IN SHAANXI PROVINCE

\begin{tabular}{|c|c|c|c|c|c|}
\hline Year & $\begin{array}{l}\text { Per capita } \\
\text { disposable } \\
\text { income of rural } \\
\text { residents (yuan) }\end{array}$ & $\begin{array}{c}\text { Rural loans } \\
\text { (\$100million) }\end{array}$ & $\begin{array}{l}\quad \text { Agricultural } \\
\text { Investment } \\
\text { (\$100million) }\end{array}$ & $\begin{array}{l}\text { Rural loans / } \\
\text { rural population } \\
\text { (yuan) }\end{array}$ & $\begin{array}{c}\text { Agricultural } \\
\text { investment / rural } \\
\text { population (yuan) }\end{array}$ \\
\hline 2001 & 1490.8 & 276.26 & 25.42 & 1139.22 & 104.82 \\
\hline 2002 & 1596.25 & 316.25 & 31.98 & 1321.01 & 133.58 \\
\hline 2003 & 1675.66 & 362 & 47.9 & 1529.36 & 202.37 \\
\hline 2004 & 1866.52 & 423.83 & 30.27 & 1808.92 & 129.19 \\
\hline 2005 & 2052.63 & 476.64 & 32.21 & 2058.03 & 139.08 \\
\hline 2006 & 2260.19 & 437.59 & 45.35 & 1943.12 & 201.37 \\
\hline 2007 & 2644.69 & 481.65 & 57.61 & 2187.33 & 261.63 \\
\hline 2008 & 3136.46 & 540.71 & 90.37 & 2511.43 & 419.74 \\
\hline 2009 & 3437.55 & 713.87 & 162.33 & 3389.69 & 770.80 \\
\hline 2010 & 4105 & 844.79 & 212.84 & 4165.63 & 1049.50 \\
\hline 2011 & 5028 & 975.56 & 343.9 & 4944.55 & 1743.03 \\
\hline 2012 & 5763 & 1111.89 & 443.98 & 5926.92 & 2366.63 \\
\hline 2013 & 6503 & 1322.45 & 524.09 & 7214.67 & 2859.19 \\
\hline 2014 & 7932 & 1678.25 & 671.3 & 9375.70 & 3750.28 \\
\hline 2015 & 8689 & 1992.83 & 1006.48 & 11400.63 & 5757.89 \\
\hline
\end{tabular}

\section{B. Parameter estimation}

Using Eviews 8. 0 software, the regression results are as follows. 


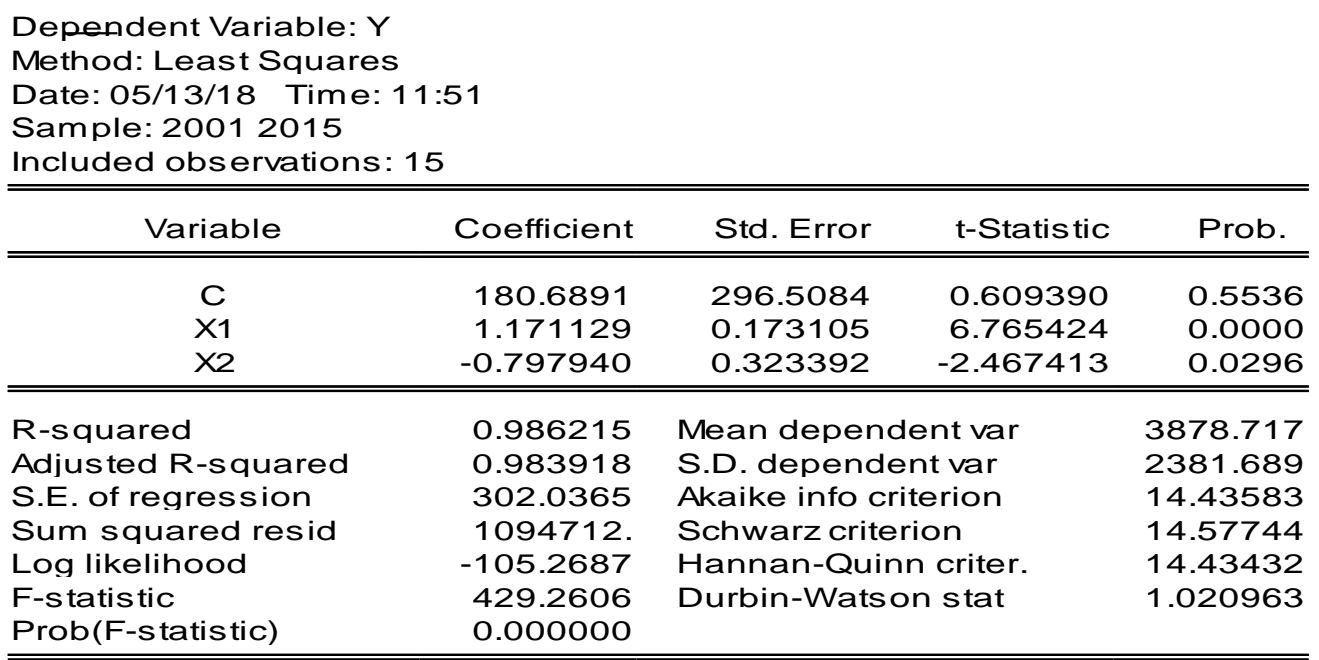

Fig. 3 Regression analysis of rural residents' per capita net income and rural financial related variables in Shaanxi Province

\section{THE RESULT OF MULTIVARIATE LINEAR REGRESSION}

Table 3-1 is the analysis result of the correlation between the per capita net income of rural residents and rural loans and agricultural investment by using the multivariate linear regression model. It can be seen in the table that the fitting degree of the model is very good, which can reflect the data of $98.00 \%$ sample. It can be concluded from the table that for every unit of increase in rural loans, the average per capita net income of rural residents will increase by 1.17 units, and the per capita net income of rural residents is positively correlated with rural loans, which is consistent with theoretical analysis and empirical judgment. Rural loans to rural residents per capita net income has a role in promoting. T test is carried out on the per capita net income of rural residents affected by rural loans: given a significant level of 0. 05, the degree of freedom of the $t$ distribution table is found to be the critical value of $\mathrm{n}-\mathrm{k}=14$ (t) 2.145 . From the results of the econometric analysis of figure $3-1$, it can be seen that the corresponding $t$ statistics are obtained $\mathrm{t}=5.0116>2.145$, which indicates that, at a significant level, The explanatory variable "per capita rural loan" has a significant effect on the explained variable "per capita net income of rural residents". This is consistent with the theoretical facts.

There is a negative correlation between the per capita net income of rural residents and agricultural investment, which may not be consistent with the existing theories, indicating that the agricultural investment system in Shaanxi Province is not perfect, and the structure and policies are insufficient. Even the emergence of agricultural investment to a certain extent negative impact on the per capita net income of rural residents. However, "per capita agricultural investment" is not significant for "rural residents' per capita net income," indicating that the impact of agricultural investment on farmers' income is not obvious, and agricultural investment does not play a role in promoting farmers' income. This shows that the agricultural investment environment needs to be improved.

\section{THE DISCUSSION OF THE EMPIRICAL RESULTS}

From the empirical analysis of the above model, it is found that the main variable per capita rural loan is the main content of this study has a positive correlation with the per capita net income of rural residents, combined with the statistical data sources from 2001 to 2015 . Increasing the investment of loan funds to rural areas can not only improve the consumption level of rural residents, but also increase the gross domestic product. Therefore, Shaanxi Province should increase the scale of lending in rural areas, increase the number of rural financial institutions, cover more areas, benefit more people, better meet the needs of people in poor areas, and promote the development of agriculture, rural areas and farmers. However, at present, there are many rural loansProblem, large capital outflow, rural residents per capita net income growth slow, rural loans are very small.

\section{CONCLUSIONS AND POLICY IMPLICATIONS}

\section{A. Main conclusions}

This paper finds that rural loans do have a positive impact on farmers' income, but there are also shortcomings. The withdrawal of financial institutions in rural areas has resulted in a serious shortage of rural financial services and a serious outflow of funds. The development of rural finance has increased the vitality of capital in rural areas and brought convenience to those who need it. Therefore, many scholars began to study the development of rural finance in the form of rural loans. The question of whether economic growth in rural areas can be promoted. Based on the theory and data, this paper deeply analyzes the relationship between rural loans and farmers' income in Shaanxi Province. The empirical study shows that the rural areas lend to the rural areas. However, there are many problems in the process of rural financial development. However, in the course of rural financial development, there are many problems, we are based on facts and put forward specific settlement measures, which can promote the overall financial support agriculture development of our country to a certain extent. 


\section{B. Policy implications}

First, the construction of rural credit system to solve the outflow of funds. The farmer is the main body of rural area construction. Due to asymmetric information moral hazard and adverse selection, rural loan authorities can not go deep into every household to make a comprehensive understanding of the situation, can only be based on mutual trust between the two parties to carry out business. The government should publicize the importance of honesty and credit, create a good environment of mutual trust for rural areas, make residents learn more and read newspapers, and increase their own quality. It is necessary for farmers to realize the importance of rural loan law and establish a credit system in rural areas, which can relax the capital quota for good credit farmers and lower credit rating for farmers. Strict scrutiny. Finally, we should be responsible for arrears of loans and evading repayment.

Second, improve the mode of operation, increase the scale of loans and improve efficiency. Financial institutions in rural areas are profit-making organizations and the main institutions for the distribution of micro-credit in rural areas. Therefore, we should be good at guiding the sustainable and rational development of rural financial institutions, but also provide financial assistance for the rural vulnerable groups. Financial institutions should make their funds public and implement a strict financial examination and approval system. Rural credit institutions should take the initiative to carry out research in rural areas, change from passive to active, guide out potential customer groups, and help them get rich on the road to get in touch with farmers in time, and follow up with them. Tracing funds, and institutions to strengthen their own quality construction, improve the quality and efficiency of services.

Third, to provide innovative products and services. The rural areas have a single existence of financial products and restrict the expansion and implementation of rural credit scale to a large extent. Therefore, it is important to provide innovative products and innovative services to a large extent. As a result, it is necessary to provide innovative products and innovative services in combination with the actual situation of rural areas. As a result, institutions should play a credit rating system, reduce the demand for mortgage and pledge of farmers and small and medium - sized enterprises in rural areas, such as household credit, forest rights pledge credit and batch order agriculture. New use of "one-card" to save transaction costs, improve the information of farmers loans, with the help of the power of the Internet, improve the allocation of resources in rural areas.

\section{REFERENCES}

[1] Bai Yongping. Study on Rural Finance supporting Rural Economic Development in Shaanxi Province [D]. Northwest University of Agriculture and Forestry Science and Technology. (In Chinese)

[2] Kong Ning. Mutual guarantee invigorating Rural loans [J]. China Finance 5: 100-104. (In Chinese)

[3] Li Jieman. A study on the nonlinear effect of Rural Microcredit on Farmers' income [D]. Hunan University. (In Chinese)

[4] Liu Yi. A study on the relationship between Rural Economic growth and Financial Development in Shaanxi Province [D]. Northwest University 2010. (In Chinese)

[5] Xie Meng. Study on supporting agriculture refinancing in Shaanxi [D]. Northwest Agriculture and Forestry University, 2016.(In Chinese)

[6] Study on the effect of Rural Microcredit on Farmers' Income increase [J]. Su Nan. Journal of Guangxi University. (In Chinese)

[7] Li Changsheng, Yan Xuanzhou. The influence of Agricultural loan on Farmers' Income: a dynamic Analysis based on State Space Model [J]. Journal of Agricultural and Forestry Economics and Management: 04-284-291. (In Chinese)

[8] Xinfang HAN, Li MA. On generalized feynman-kac transformation for markov processes associated with semi-dirichlet forms [J]. Acta Mathematica Scientia, 2016, 36(2): 345-351.

[9] Studies on phosphorescence and trapping effects of Mn-doped and undoped zinc germinates [J]. Zhiyi He, Li Ma, Xiaojun Wang. Journal of Luminescence., 2016, 12(3): 457-462. 